\title{
Infância, participação e socialização
}

\section{Infancia, participación y socialización}

\section{Childhood, participation, and socialization}

\author{
Lisandra Ogg Gomes \\ ORCID ID: 0000-0002-3601-7758 \\ Universidade do Estado do Rio de Janeiro (EDU/PROPEd), Brasil
}

Autor referente: lisandraogg@yahoo.com.br

Historia editorial

Recibido: 04/01/2021

Aceptado: 16/04/2021

\section{RESUMO}

Neste artigo apresento algumas das análises teóricas desenvolvidas no âmbito da pesquisa, ainda em curso, intitulada $A$ participação da infância na sociedade brasileira. Nesta investigação teórica-empírica objetivo conhecer, analisar e compreender as práticas, os discursos e as dinâmicas sociais que reconhecem as crianças brasileiras como sujeitos de direitos e atores sociais. Com base no campo dos Estudos da Infância, com atenção especial à Educação, Política e Sociologia da Infância, aponto o maior reconhecimento social e legal das crianças, promovendo legitimação e participação da infância na sociedade. Também pondero que a atualização do conceito de socialização compreende a ação reflexiva e um processo ativo, no qual é o indivíduo que se faz, se desfaz e se refaz a partir das e nas relações sociais. Assim, assumo a infância como a geração que agrega crianças que participam e se socializam nas diferentes instâncias sociais e interferem nas dinâmicas, determinações e prescrições institucionais e as reorganizam. Portanto, este artigo é de caráter teórico a respeito do sentido da participação e dos processos de socialização na vida das crianças, em correlação aos impactos sociopolíticos e culturais na infância.

Palavras-chave: Infância; participação; socialização.

\section{RESUMEN}

En este artículo presento análisis teóricos desarrollados en el ámbito de la investigación, aún en transcurso, con el título: "La participación de la infancia en la sociedad brasileña". En esta investigación teórico-empírica pretendo conocer, analizar y comprender las prácticas, los discursos y las dinámicas 
sociales que reconocen a los niños y las niñas brasileñas como sujetos de derechos y actores sociales. Fundamentada en el campo de los Estudios sobre la Infancia, con especial atención a la Educación, Política y Sociología de la Infancia, señalo el mayor reconocimiento social y legal de los niños y de las niñas, promoviendo la legitimación y participación de ellos en la sociedad. También considero que la actualización del concepto de socialización comprende la acción reflexiva $y$ un proceso activo, permitiendo al individuo se hacer, se deshacer y se rehacer desde las y en las relaciones sociales. Así, asumo la infancia como la generación que agrega sujetos sociales que participan y socializan en diferentes instancias sociales e interfieren en las dinámicas, determinaciones y prescripciones institucionales y las reorganizan. Por lo tanto, presento aquí un artículo teórico sobre el sentido de la participación y de los procesos de socialización en la vida de las niñas y los niños, en correlación a los impactos sociopolíticos y culturales en la infancia.

Palabras clave: Infancia; participación; socialización.

\section{ABSTRACT}

In this article I present some theory analyses developed in the research, still in course, called "The participation of childhood in Brazilian society". This theoretical-empirical research aims to know, analyze, and understand the practices, discourses, and social dynamics that recognize Brazilian children as individuals with rights and as social actors. Based on the social studies field, mainly education, policy, and sociology of childhood, I indicate a great social and legal recognition of children, promoting legitimization and participation of childhood in society. I also consider that the current socialization concept includes a reflective action and an active process, in which the individual that builds, unbuilds, and rebuilds him and herself from and through in the social relations. Thus, I assume the childhood as the generation that ensembles children that participate and socialize in different social instances, they interfere and reorganize institutional dynamics, determinations, and prescriptions. Therefore, this is a theoretical article on the participation meaning and socialization processes on children's life, in correlation with the sociopolitical and cultural impact in childhood.

Keywords: Childhood; participation; socialization.

$\mathrm{M}$ inha proposta com esse artigo é apresentar e analisar as questões conceituais, portanto não empíricas, a respeito da infância, participação e socialização, que venho desenvolvendo e está em andamento no âmbito da investigação $A$ participação da infância na sociedade brasileira, que conta com 
recursos da chamada MCTIC/CNPq (Conselho Nacional de Desenvolvimento Científico e Tecnológico) nํ..28/2018-Universal e tem aprovação da Comissão de Ética em Pesquisa (COEP) - parecer 3.573.916. Esta pesquisa está em andamento no quadro do Programa de Pós-graduação em Educação (PROPEd), da Faculdade de Educação (EDU) da Universidade do Estado do Rio de Janeiro (UERJ), sendo meu principal objetivo conhecer, mapear e compreender as práticas, os discursos e as dinâmicas sociais educativas nas quais as crianças são atores sociais e sujeitos de direitos.

Pondero que este estudo tem tanto um enfoque qualitativo como quantitativo, porque concilia dados primários, em particular, os depoimentos obtidos por meio de entrevistas e análise das propostas de participação das instituições selecionadas; e dados secundários, tais como pesquisa aberta e transversal em buscador de banco de dados de publicações impressas e online de materiais acadêmicos e pedagógicos; análise de discussões em fóruns acadêmicos e políticos; e em sites educacionais que divulgam projetos e planos públicos da participação da infância na sociedade.

Também classifico esta proposta metodológica como uma quase etnográfica, pois, mesmo que não seja possível vivenciar junto com as crianças brasileiras os projetos de participação nos quais atuam, esse encontro entre pesquisadora, crianças e adultos permite estabelecer relações, listar informantes, transcrever textos, mapear campos, manter um diário e assim por diante (Geertz, 2014).

Dessa forma, a pesquisa abrange o levantamento e estudo da produção bibliográfica, especialmente a sociológica e educacional, que trata dos conceitos de socialização e participação, assim como, levanta e mapeia projetos e propostas nacionais de caráter educativo que contam com a efetiva atuação das crianças de até 12 anos - idade definida em conformidade com o Estatuto da Criança e do Adolescente (ECA) (Brasil, 1990b) - nos espaços público e privado, urbano e rural. 
Todavia, como os dados de campo ainda estão sendo levantados para uma posterior análise, considerei pertinente e importante tratar, neste artigo, dos principais conceitos que essa investigação abarca, a saber: participação, infância e a socialização das crianças no seus espaços e tempos sociais. Para essa apreciação, tomo como campo de conhecimento os Estudos da Infância, com especial atenção à Educação, Política e Sociologia da Infância, pois me parece que os conceitos elaborados nestas áreas auxiliam a compreender a constituição de ações sociopolíticas para as crianças e a infância. Ademais, o campo dos Estudos da Infância prioriza investigações centradas nas crianças e na infância, naquilo que elas têm a dizer, nas suas formas de compreensão e atuação, e busca uma desnaturalização de ideias e práticas determinadas para esses sujeitos e essa geração.

Sendo assim, organizei este artigo em dois tópicos. Para começar, pretendo abordar os conceitos de infância e socialização, e, na sequência, tratarei da infância, das crianças em relação à participação. Dessa forma, considero que seja possível analisar e compreender como a participação e a socialização impactam a vida das crianças, o que permite articulações e reflexões teóricas e práticas a respeito da infância.

\section{Socialização e infância}

É fato social toda maneira de fazer, fixada ou não, suscetível de exercer sobre o indivíduo uma coerção exterior; ou ainda, toda maneira de fazer que é geral na extensão de uma sociedade dada e, ao mesmo tempo, possui uma existência própria, independente das suas manifestações individuais. (Durkheim, 2007, p. 13).

A maneira de pensar, agir e sentir, que se dá fora da consciência individual e toma o coletivo é um fato - ou fenômeno - social, uma força imperativa e coercitiva que se impõe aos sujeitos, quer queiram ou não (Durkheim, 2007). Sendo assim, entendo a socialização e a infância como fenômenos sociais, que têm suas práticas, ideias, 
tendências e crenças produzidas, reproduzidas e difundidas pelo conjunto da sociedade, com clara atenção para as crianças e que ocorre antes mesmo do seu nascimento.

Significados, signos linguísticos, códigos e preceitos morais, costumes culturais, ou seja, as várias dimensões da vida sócio-simbólica - econômica, cultural, estética, familiar, jurídica, religiosa, por exemplo - são transmitidas tanto de forma sistemática, intencional e conscientes quanto através de ações difusas, assistemáticas, não intencionais e inconscientes, adquiridas de maneira homeopática na infância, na família, na escola, na religião e em grupos de amigos, por exemplo, os quais atuam na formação das crianças e na compreensão da realidade das quais elas participam (Setton, 2011).

Todos os fenômenos sociais, entre eles os da infância e da socialização, exigem dos sujeitos a articulação entre essa diversidade de produções coletivas. No caso da infância, as crianças ao nascerem encontram uma geração já constituída, com uma forma, um sentido e uma natureza, sendo elas compelidas a atuarem conforme preceitos latentes e manifestos socialmente determinados. Por sua vez, o conceito de socialização é constituinte para os campos sociológicos e educacionais, pois abrange os processos formativos, ou seja, a educação das pessoas, que é produto da vida coletiva e expressa as necessidades de uma época. Nos termos de Abrantes (2011, p. 121), a socialização é um "processo de constituição dos indivíduos e das sociedades, através das interações, atividades e práticas sociais, regulado por emoções, relações de poder e projetos identitários-biográficos, numa dialética entre organismos biológicos e contextos socioculturais".

Esses fenômenos sociais não se apresentam de forma natural ou espontânea, pois é no espaço societário que eles são formados, constituídos e difundidos. É também nesse espaço do social que as crianças formam suas identidades e se constituem 
como pessoas, permitindo-lhes novos ou outros sentidos e interpretações para a compreensão daquilo que transcorre nas diferentes esferas da vida.

Ocorre que os fenômenos sociais denotam uma coerção e prescrição que podem tanto conformar os sujeitos, que acreditam em uma ordem natural, quanto eles podem resistir e transgredi-los, o que acaba por gerar conflitos. Por um lado, esses processos podem ser vividos como adaptações que, muitas vezes, são significados como disposições, algo experimentado e considerado como inato pelos sujeitos, mas sem que se deem conta dos constrangimentos e imposições sociais. Por outro lado, como são construções sociais, os fenômenos podem ser modificados quando suscitam resistência às regras estabelecidas, fazendo com que os sujeitos as transgridam e questionem, buscando novas configurações. Pois,

Ainda que, de fato, eu possa libertar-me dessas regras e violá-las com sucesso, isso jamais ocorre sem que eu seja obrigado a lutar contra elas. E ainda que elas sejam finalmente vencidas, demonstram suficientemente sua força coercitiva pela resistência que se opõem. Não há inovador, mesmo afortunado, cujos empreendimentos não venham a deparar com oposições desse tipo. (Durkheim, 2007, p. 3).

Portanto, mesmo que a socialização e a infância pareçam ter uma autonomia, persistência e até naturalidade, são processos constituídos e construídos pelo conjunto da sociedade e no decorrer da sua história. São processos que têm as crianças como participantes e atuantes na relação, mediação e interação das práticas e ideias sociais que elas interpretam, mediam, (re) produzem e difundem considerando seus contextos.

A infância exige das crianças - em um grupo, comunidade ou sociedade - a socialização e o conhecimento das regras e normas para a atuação social, o compartilhamento dos seus interesses, suas perspectivas e seus incômodos, assim como, também a interação com e escuta do outro. Dessa forma, infância e 
socialização se configuram como quebra-cabeças diante da liberdade e da diversidade de escolhas e do jogo de alteridade entre sujeitos.

Esclareço, assim, que socialização e infância não são fenômenos que se precipitam unicamente sobre as crianças, mas abrangem a todos na sociedade da mesma forma como estão em correlação com outros fenômenos, pois suas regras demonstram certas concepções da sociedade e da vida coletiva (Durkheim, 2007). No caso da socialização, ela ocorre entre as crianças - nos seus grupos de pares -, entre elas e os jovens, adultos e velhos e delas com as instituições, e com as formulações daquilo que foi previamente determinado para a continuidade do seu desenvolvimento individual e coletivo. Por sua vez, a infância é uma categoria geracional produzida e que agrega práticas e ideias dos adultos para as crianças, dos adultos para as gerações dos adultos, juventude e velhice sobre a infância e também aquelas produzidas pelas próprias crianças.

A dificuldade atual de analisar esses fatos sociais - da infância e socialização - ocorre da apreciação de diferentes componentes e como eles se organizam, pois, como pondera Durkheim (2007), um fato social deve ser compreendido na articulação com outros fatos. Isso permite compreender que da mesma forma que as crianças são socializadas e a elas é determinada a infância, elas se socializam e socializam aqueles que estão ao seu redor, reconfigurando sua geração. Sendo assim, se a socialização fosse analisada apenas por uma via ou somente como um processo de imposição, a infância passaria a ser considerada apenas como uma fase de conformação às estruturas da sociedade. Porém, como as crianças adaptam-se, são atuantes, participantes e questionam as regras, aos poucos estas normativas vão sendo revistas no âmbito societário.

As crianças e a infância participam da macro e microestrutura, o que significa que elas são parte da estrutura da sociedade. Assim, elas produzem, com seus pares, suas próprias atividades - ainda que invisibilizadas e marginalizadas por essa mesma 
sociedade - e constituem-nas a partir de incessantes conexões que estabelecem com as demais pessoas e instituições.

Diante desta questão e ainda que em processo de análise dos dados primários, verificou-se a partir do levantamento realizado na pesquisa apontada anteriormente que as crianças impulsionaram e produziram ações de intervenção lúdica, participaram da gestão e monitoramento de políticas pública, projetos nos movimentos populares, criação de conselhos escolares e comunitários e atividades difundidas em aparelhos comunicacionais. No caso específico dos conselhos organizados em escolas, se destacaram duas propostas, sendo uma pública e situada na cidade de São Paulo, e a outra privada e localizada no Rio de Janeiro. Em São Paulo as crianças mobilizaram ações que abordaram a identidade da instituição e pleitearam eleições para a escolha de um novo nome para a escola com mais representatividade para sua comunidade interna e externa. Já na escola da cidade do Rio de Janeiro, as crianças em parceria com suas família, docentes e funcionários da instituições propuseram projetos que foram desenvolvidos no decorrer do ano e que afetaram de modo significativo a comunidade escolar. Um exemplo é o projeto Moitará, em referência a um ritual que ocorre entre povos do Parque Indígena do Xingu, que teve por objetivo ser um momento de dedicação à pesquisa e um espaço de troca de saberes entre estudantes, para os estudantes e com os estudantes, envolvendo crianças da educação infantil ao ensino médio.

Portanto, para compreender a infância e as formas como as crianças se socializam é preciso considerar os efeitos produzidos por suas ações, manifestações e como práticas e ideias são difundidas e utilizadas no domínio coletivo - por adultos, jovens e velhos. Ainda que seja um processo moroso, ele tem se revelado necessário e relevante na reconfiguração da infância e da sua socialização, por envolver ideias e práticas para a infância e o socializar-se das crianças. Essas novas configurações reorganizam aquilo que foi definido para a geração da infância, que sofre a 
socialização da sociedade, mas a qual só tem efeito porque as crianças são atuantes e participam dessa mesma sociedade, porque essa é uma ação constituída por sujeitos, por aqueles que fazem acontecer, que atuam e são agentes de seus atos. Ou seja,

[...] o processo de socialização das sociedades atuais é um espaço plural de múltiplas referências identitárias. Ou seja, a modernidade caracteriza-se por oferecer um ambiente social no qual o indivíduo encontra condições de forjar um sistema híbrido de referências disposicionais, mesclando influências em um sistema de esquemas coerentes, ainda que heterogêneos. (Setton, 2011, p. 713).

A infância abarca essa diversidade de experiências, de esquemas e interações, que permite às crianças viver suas infâncias de diferentes modos, como já apontaram pesquisa e documentos nacionais e internacionais. Assim, é preciso ampliar o debate sobre a infância e a socialização e reconhecer que "[...] criança é uma pessoa de direito que possui capacidades peculiares para agir social e politicamente" (Tironi, 2017, p. 2148) - análise que será realizada na sequência.

\section{Infância, crianças e participação}

Desde que a Declaração Universal dos Direitos da Criança (ONU, 1959) foi aprovada em 20 de dezembro de 1959 na Assembleia Geral da Organização das Nações Unidas (ONU), entende-se que se inicia, ainda que vagarosamente, um movimento de atenção àquilo que diz respeito e afeta a infância e as crianças. Rosemberg e Mariano (2010) indicam que o principal objetivo desta lei foi a proteção das crianças das mazelas sociopolíticas e econômicas produzidas pela sociedade. Posteriormente e após extenso debate para a construção e aprovação da Convenção sobre os Direitos das Crianças (CDC) (Brasil, 1990a), foram evidenciados, ampliados e tornam-se manifestos os 3-Ps: proteção, provisão e participação. 
Se a proteção e provisão já eram temas mais enfatizados e esclarecidos na sociedade, destaco que o tema da participação das crianças passo a passo tornou-se relevante para o campo dos Estudos da Infância. De acordo com Graham e Fitzgerald (2010), esta discussão envolve quatro questões chaves: a) as ambiguidades que constituem a participação; b) a complexa relação entre possibilidades e limites de participação; c) ir além das tensões é re-imaginar a participação das crianças em termos de reconhecimento e, como tal, refletir sobre o que poderia constituir um reconhecimento mais profundo do status e da voz das crianças como participantes na vida contemporânea; d) uma abordagem dialógica de participação capaz de reconhecer, respeitar e integrar as compreensões ricas e complexas que emergem através da relação dialógica e prática com as crianças.

Considerando essas questões, sabe-se que a situação das crianças no mundo é muito diversa, em razão das condições de cada país, pois a infância é afetada sobremaneira pela estrutura e conjuntura da qual participa e na qual está inserida. Deste modo, entendo que essa geração enquadra-se como uma minoria social, no sentido de estar sempre em situação de desvantagem no acesso aos meios, recursos e na relação de poder quando comparada às demais gerações, como com a juventude, velhice e, especialmente, a idade adulta, categorias que têm maiores acessos a recursos e habilidades para enfrentar os desafios externos e crises conjunturais.

Para ilustrar essa análise, nos casos estudados e indicados anteriormente, as crianças ainda precisam contar com adultos que se interessam por suas causas, como, foi possível examinar nas ações das crianças Sem-terrinha do Movimento dos Trabalhadores Rurais Sem Terra/MST, que buscam desde 1994, por meio de encontros promovidos por e com lideranças do movimento, garantir o direito à escola nos assentamentos e acampamentos Sem Terra, um direito já estabelecido em lei. Assim, concordo com Sgritta (1997), Tironi (2017) e Canclini (1995) de que para a infância ainda não foi garantida uma real cidadania, mas algo secundário. Embora seja 
manifesta uma cidadania para as crianças - pois elas têm direitos legitimados pelo Estado e possuem práticas culturais e sociais que dão sentido de pertencimento e solidariedade -, o reconhecimento social delas ainda é parcial. As crianças ainda não são titulares de plenos direitos e tampouco são consideradas legítimas cidadãs, porque não têm representação direta nas instâncias sociopolíticas e são tuteladas pelos adultos, que, muitas vezes, sem saber ou atentar-se para as crianças, de modo paternalista decidem o que é bom para elas, tomam decisões e têm ações diretas e indiretas que interferem sobremaneira na geração e na vida das crianças.

A compreensão da criança como pessoa de direito dotada de capacidade de agir, coloca-a na posição de detentora de direitos e também de responsabilidades (uma vez que o reconhecimento é intersubjetivo). Isto não significa que seus direitos e responsabilidades serão exercidos da mesma maneira com que os adultos o fazem, nem que não haverá prescrições jurídicas de proteção e dever diferenciadas para adultos e crianças (como de fato há). Cada um age na medida de suas capacidades pessoais, sendo por isso que as relações intersubjetivas são consideradas assimétricas. (Tironi, 2017, p. 2164).

Como se vê, é manifesto que as crianças são atores sociais, elas são participantes e atuantes em seus tempos e espaços. Assim, os cenários sociais e os estudos acadêmicos têm demonstrado uma relativa atenção para o modo de participação das crianças referente às questões públicas, restritas e amplas, que Ihes dizem respeito; e à posição da infância na estrutura da sociedade como uma categoria geracional.

Este processo pode ser percebido a partir do século $X X$ com alguns marcadores relevantes e que incidiram no modo de considerar e compreender a infância, entre eles, aponto o estudo de Ariès (1999) com a construção sócio-histórica da infância, os debates ocorridos por mais de 10 anos para elaboração da CDC (Brasil, 1990a), a 
promulgação da Constituição brasileira (Brasil, 1988) que reconhece a criança como sujeito de direito e, na sequência, a aprovação do ECA (Brasil, 1990b).

É importante assinalar que a CDC tem caráter mandatório e contempla direitos civis e políticos; econômicos, sociais e culturais; e direitos especiais (de proteção) (Rosemberg \& Mariano, 2010). Ao adotá-la o Brasil "assumiu o compromisso de construir uma ordem legal interna voltada para sua efetivação" (Arantes, 2012, p. 46). Ademais, a aprovação dessas leis garantiu às crianças brasileiras direitos como, por exemplo, de serem ouvidas e expressarem suas opiniões; terem acesso à liberdade de expressão, pensamento, associação e à informação; e a participação deve promover o interesse delas, com igualdade de direitos e sem discriminação (Ação Educativa, 2013).

Todavia, essa ordem esbarra na conjuntura e estrutura da sociedade brasileira que é extremamente desigual nas questões econômicas, sociais, raciais, etárias e de gênero. Diante desse fato e entre os debates que cercam a infância, na atualidade a participação ainda é um tema delicado, pois essa geração não é consultada sobre aquilo que Ihe diz respeito e também não é escutada sobre seus interesses. Além disso, a infância também é caracterizada, constituída e atrelada a dogmas culturais, como, por exemplo, aqueles que indicam sua irresponsabilidade, irracionalidade e incapacidade societária (Benedict, 2009). Dessa forma, a importância dada às crianças é ainda enquanto um vir a ser, como sujeitos de um futuro, colocadas em espera e preparação para um tempo que estará por vir (Sgritta, 1997).

Acontece que as crianças vivem suas infâncias no aqui e agora e não há um momento específico para uma hipotética entrada na sociedade, pois elas estão e nascem dentro da e na sociedade, igualmente suas formas de atuação não serão únicas e tampouco são a-históricas, pois, como já dito, os parâmetros sociais, afetivos e cognitivos interferem na sua relação com os outros sujeitos e suas culturas. Por estar e participar da cultura, as crianças inserem novos entendimentos, olhares, questionamentos e 
propõem outras formas de atuação, demandando dos demais indivíduos interações e (re)organizações. Portanto, não há como ficar indiferente à participação das crianças em seus tempos e espaços. No decorrer da pesquisa foi possível verificar que as crianças têm participado e proposto a revitalização de espaços públicos por elas utilizados, projetos em suas escolas nos quais atuam como principais atores e encontros regionais e nacionais para a divulgação e o respeito aos seus direitos básicos e já garantidos por lei. São, portanto, ações que evidenciam as formas como crianças e adultos se relacionam e fortalecem a democracia participativa, entendida como o exercício da soberania popular (Ação Educativa, 2013).

Como se vê, essas análises sobre o futuro e presente não são uma recusa à previdência, pois, como aponta Cassirer (1994, p. 93),

[...] o futuro avistado pelo homem estende-se por uma área muito mais ampla, e seu planejamento é muito mais consciente e cuidadoso. Mas isso ainda pertence ao domínio da prudência, não ao da sabedoria. O termo "prudência" (prudentia) está etimologicamente ligado a "providência" (providentia). Significa a capacidade de prever eventos futuros e preparar-se para as necessidades futuras.

Certamente que para as crianças, como para qualquer pessoa, há preparações e, no caso da infância, há outros imperativos, pois diante de uma sociedade centrada no adulto, isto é, adultocêntrica, elas necessitam de proteção e provisão para crescerem e se desenvolverem, pois, como já apontado, é notória sua vulnerabilidade estrutural e também a natural.

Todavia, para além dos meandros da proteção e provisão, a participação passa a ser um aspecto igualmente importante, que envolve ambiguidades e é tenso, pois exige uma ação cidadã. Como afirma Qvortrup (2010), a proteção garante a não exposição das crianças aos riscos de uma sociedade moderna, mas igualmente elas precisam se experimentar enquanto pessoas que contribuem para a sociedade, elas precisam 
estar em constante interação com diferentes sujeitos, tomar parte do seu tempo e espaço e, se possível, experienciar "sempre de novo, centenas e milhares de vezes" (Benjamin, 2002, p. 101). Portanto, é atuando e participando que as crianças aprendem sobre as questões sociais, culturais, econômicas, ecológicas, entre outras. Dessa forma, a participação está vinculada ao coletivo e à política, ou seja, se insere no campo da ação, pois é um realizar, ser parte, tomar ou ter parte em algo a partir de duas bases, uma afetiva e outra instrumental. A afetiva envolve o sentimento de prazer, apreço e cuidado em realizar algo com outras pessoas, assumindo uma responsabilidade com si e outros; a instrumental abrange a ação coletiva e o interesse comum, portanto é mais efetiva do que aquela realizada de forma individual (Bordenave, 1983; Batthyány, Genta, \& Perrotta, 2014).

Por meio da participação são estabelecidas relações de interdependência entre sujeitos e entre sujeitos e instituições. O conceito de interdependência é importante na medida em que permite entender as composições que os sujeitos formam (Elias, 1994). A interdependência confere sentido às relações e interações ocorridas entre as crianças, entre elas com jovens, adultos e velhos, e entre elas e as instâncias socializadoras. Por meio dessas interações é possível conhecer a ótica das crianças, ou seja, como elas observam e compreendem a sociedade e os problemas sociais que Ihes acometem ou não. É participando que as crianças (re) organizam, transgridem e modificam seus espaços e tempos, pois ao interpretarem os fatos ao seu modo, causam alterações e renovações de ideias e práticas socioculturais.

Contudo, não basta apenas querer participar, pois isso demanda o aceite de outros sujeitos e são necessárias ações políticas ideológicas, pontuais e representativas. Como ideológica, a noção de política responde a questões de orientação, de um caminho a seguir. Por sua vez, as políticas respondem a problemas práticos, que resultarão em decisões pontuais para a geração ou grupos específicos. Por fim, as políticas devem representar de forma adequada a infância, os direitos e interesses das 
crianças, visto que para elas ainda é determinado um papel secundário e porque ainda não praticam atos civis (Qvortrup, 2010).

Considerando essas análises, a participação está relacionada à democracia vivenciada no país. No caso brasileiro temos visto um governo de extrema-direita, eleito para o mandado de 2019-2022, que tem se utilizado da infância para disputa ideológica e moral. Se soma a isso uma conjuntura complexa e tensa engendrada pela:

(...) existência de um desencanto geral e uma certa desilusão com o restabelecimento das democracias na América Latina que falharam em cumprir suas promessas de superar os problemas sociais, o clientelismo e a corrupção, ou de consolidar formas de participação popular (Butler \& Princeswall, 2012, p. 112).

Nesse sentido, as inter-relações e interdependência da infância com a estrutura da sociedade assumem formas de socialização mais politizadas, compreendendo que essa ação exige: a) leis que precisam ser decididas em processos regulares e amplamente participativos; b) respeito ao bem público, acima do interesse privado e patriarcal; c) sentido de responsabilidade no exercício do poder (Benevides, 1996).

\section{Considerações finais}

Essa pesquisa, que ainda está em andamento, busca ampliar o debate sobre a infância e a socialização vinculados ao conceito de participação das crianças na sociedade. É uma tentativa de compreender como a partir desses fenômenos os sujeitos atuam. Dessa forma, a participação foi aqui examinada como uma ação de sujeitos implicados a outros sujeitos, sua geração e instituições, envoltos em processos de socialização, que indicam formas de um ser e estar em sociedade. Nesse sentido, a socialização afeta a todos que participam da esfera societária, com interações, relações e interdependências alteritárias e de atenção às identidades. 
Não há como não estar e viver em sociedade e não participar, mas é possível que, na relação de poder, essa mesma sociedade torne invisível ou marginalize alguns sujeitos e suas ações, como no caso das crianças e da infância. Cada geração e sujeito é chamado de diferentes formas para essa ação que às vezes é praticada de forma manifesta ou latente. Todavia, torna-se evidente que é atuando que cada membro da sociedade conhece seus espaços e tempos, as determinações, normas, códigos e preceitos socioculturais e esse aprendizado não ocorre apenas por uma via, pois cada pessoa contribui para o seu próprio processo de socialização e construção da geração como interfere nos de outros.

Considerando as sociedades democráticas, a importância da participação - entendida como um espaço de escuta, atenção e posicionamento político - possibilita o desenvolvimento da solidariedade e de uma consciência coletiva que se compromete com todos os envolvidos e as questões colocadas em debate. Dessa forma, as pesquisas acadêmicas sobre crianças, a respeito da infância e da participação têm revelado que envolvê-las em processos de socialização e com ações pautadas para uma ordem política e democrática permitem alterações e renovações de ideias e práticas socioculturais.

Entretanto, os estudos também advertem que é preciso uma apreciação mais crítica para a forma como esses conceitos têm sido empregados, pois a análise da participação da infância na sociedade traz o embate das relações de poder entre gerações e novos valores e entendimentos, com a pretensão da manutenção social. Portanto, deseja-se que esse debate faça conhecer como as crianças respondem aos problemas da sua época e como as instituições têm ampliado e garantido a participação da infância, na busca por relações sociais mais simétricas, portanto, mais democráticas e menos excludentes. 


\section{Referências}

Abrantes, P. (2011). Para uma teoria da socialização. Sociologia, Revista da Faculdade de Letras da Universidade do Porto, XXI, 121-139. Recuperado de http://ojs.letras.up.pt/index.php/Sociologia/article/view/2229

Ação Educativa (2013). A participação de crianças e adolescentes e os Planos de Educação. São Paulo: Ação Educativa.

Arantes, E. M. de M. (2012). Direitos da criança e do adolescente: um debate necessário. Psicologia Clínica. 24(01), 45-56. doi.org/10.1590/S010356652012000100004

Ariès, P. (1999). Padri e figli nell'Europa medievale e moderna. Roma: Editori Laterza.

Batthyány, K., Genta, N., \& Perrotta, V. (2014). La dimensión de génere en el saber experto en cuidado infantil. Psicología, Conocimiento y Sociedad, 4(1), 33-58. https://revista.psico.edu.uy/index.php/revpsicologia/article/view/197

Benedict, R. (2009). Continuità e descontinuità nel condizionamento culturale. Em R. Lenine, \& R. New. Antropologia e infanzia. Sviluppo, cura, educazione: studi classici e contemporanei (pp. 65-75). Milano: Raffaello Corina Editore.

Benevides, M. V. (1996). Educação para a democracia. Lua Nova, 38, 223-237. https://doi.org/10.1590/S0102-64451996000200011

Benjamin, W. (2002). Reflexões: a criança, o brinquedo, a educação. São Paulo: Duas Cidades; Editora 34.

Bordenave, J. E. D. (1983). O que é participação. São Paulo: Editora Brasiliense.

Brasil. (1990a). Decreto 99.710, de 21 de novembro de 1990. [Brasilia]: Presidência da $\begin{array}{llll}\text { República. } & \text { Casa } & \text { Civil. } & \text { Recuperado de }\end{array}$ http://www.planalto.gov.br/ccivil_03/decreto/1990-1994/d99710.htm

Brasil. (1990b). Lei $n^{\circ}$ 8.069, de 13 de julho de 1990. [Brasilia]: Presidência da República.

Casa

Civil.

Recuperado

de http://www.planalto.gov.br/ccivil_03/leis//8069.htm 
Brasil. Constituição (1988). Constituição da República Federativa do Brasil. [Brasilia]: Presidência da República. Casa Civil. Recuperado de http://www.planalto.gov.br/ccivil_03/constituicao/constituicao.htm

Butler, U. M.; \& Princeswall, M. (2012). Culturas de participação: jovens e suas percepções e práticas de cidadania. O social da questão, 15(27), 101-126. Recuperado de http://osocialemquestao.ser.pucrio.br/media/OSocial27_Butler_Princeswal1.pdf

Canclini, N. G. (1995). Consumidores e cidadãos: conflitos multiculturais da globalização. Rio de Janeiro: Editora UFRJ.

Cassirer, E. (1994). Ensaios sobre o homem: introdução a uma filosofia da cultura humana. São Paulo: Martins Fontes.

Durkheim, É. (2007). As regras do método sociológico. São Paulo: Martins Fontes.

Elias, N. (1994). A sociedade dos indivíduos. Rio de Janeiro: Jorge Zahar.

Geertz, C. (2014). A interpretação das culturas. Rio de Janeiro: LTC.

Graham, A., \& Fitzgerald, R. (2010). Progressing children's participation: exploring the potential of a dialogical turn. Childhood, 17(03), 343-359. https://doi.org/10.1177/0907568210369219

Qvortrup, J (2010). Infância e política. Cadernos de Pesquisa, 40(141), 777-792. https://doi.org/10.1590/S0100-15742010000300006

Rosemberg, F., \& Mariano, C. L. S. (2010). Convenção Internacional sobre os Direitos das Crianças: debates e tensões. Cadernos de Pesquisa, 40(141), 693-728. http://dx.doi.org/10.1590/S0100-15742010000300003

Setton, M. da G. J. (2011). Teorias da socialização: um estudo sobre as relações entre indivíduo e sociedade. Educação e Pesquisa, 37(4), 711-724. https://doi.org/10.1590/S1517-97022011000400003 
Sgritta, G. B. (1997). La cittadinanza 'negata'. Em G. Maggioni; \& C. Baraldi. Cittadinanza dei bambini e costruzione sociale dell'infanzia. Urbino: Edizioni QuattroVenti.

Tironi, S. (2017). Criança, participação política e reconhecimento. Revista de Direito e Práxis. 08(03), 2146-2172. https://doi.org/10.1590/2179-8966/2017/23563

\section{Declaración de contribución de autores}

LOG contribuyó en la totalidad del artículo.

\section{Editor de sección}

Las editoras de sección de este artículo fueron Magali Reis y Mariela Losso.

ORCID ID: 0000-0001-6741-1638

ORCID ID: 0000-0001-7395-1163

Formato de citación

Ogg Gomes, L. (2021). Infância, participação e socialização. Psicología, Conocimiento y Sociedad, 11(1), 129-147. doi: http://dx.doi.org/10.26864/PCS.v11.n1.6 